\title{
Consumer acceptance and sensorial analysis of bread with grape seed flour
}

\author{
Oana Bianca Oprea ${ }^{1, *}$ and Liviu Gaceu ${ }^{1,2,3}$ \\ ${ }^{1}$ Transilvania University of Brasov, Faculty of Food and Tourism, Department of Engineering and \\ Management of Food and Tourism, Castelului street no.148, Brasov, Romania \\ ${ }^{2}$ Romanian Academy, CSCBAS \&CE-MONT Centre / INCE - Romanian Academy \\ ${ }^{3}$ Academy of Romanian Scientists, Assoc. m. Academy of Romanian Scientists
}

\begin{abstract}
Grape seed flour from grape marc, a waste product obtained during winemaking, was analyzed for use in bread production due to its potential health benefits. This study evaluated the consumer acceptance and physical properties of bread made with varying quantities of grape seed flour. Dough and breads were prepared using different levels of replacement of wheat flour with grape seed flour (0 to $9 \%$ ). The method used for the research was that of the scoring scale, and the marks given by the 15 properly trained panelists indicated that a percentage of $5 \%$ grape seed flour by the indirect method leads to statistic characteristics close to those of black bread regarding Standard SR 878/1996.
\end{abstract}

\section{Introduction}

The European bakery sector consists of over 190,000 SMEs and 2,200 large companies, with over 2 million employees. In 2019, at EU27 level, the bread market totaled approximately 32 million tones, with an estimated value of 79 billion $€$. Bread consumption differs greatly in European countries, the highest consumption is recorded in Turkey, Bulgaria, and Romania (approximately $96 \mathrm{~kg}$ ), and the lowest consumption is recorded in the United Kingdom (approximately $32 \mathrm{~kg}$ ), the offer of bread products being more and more diverse. Bakery products are part of a market centered on the demand for conventional food, in which the innovative element gradually takes over $[1,2,3]$. According to several statistics, young people, people with higher education, with higher incomes, especially in urban areas, are reorienting towards new assortments, at a time when the reduction of consumption is becoming an increasing trend. According to statistics released by the National Institute of Statistics, the average consumption of bread in Romania decreased from $9.2 \mathrm{~kg} /$ month per capita in 2008 to about $8 \mathrm{~kg} /$ month per capita in 2018 (fig.1).

However, Romania has one of the highest bread consumption in Europe, near Bulgaria and Turkey, so this research has a big importance.

Bread - functional food, becomes a promising category on the bakery market due to concerns to improve the nutritional profile. As the main direction of development, there is a

\footnotetext{
${ }^{*}$ Corresponding author: oprea.oana.bianca@,unitbv.ro
} 
consumer preference for improved white bread, through the use of cereals and other seeds as functional ingredients rich in dietary fiber, antioxidants and other valuable nutrients [4, $5,6,7]$. Improving bakery products with grape seed powder is an effective way to improve nutritional characteristics, especially through the intake of fiber, $\mathrm{K}, \mathrm{Mg}, \mathrm{Ca}[8,9,10]$.

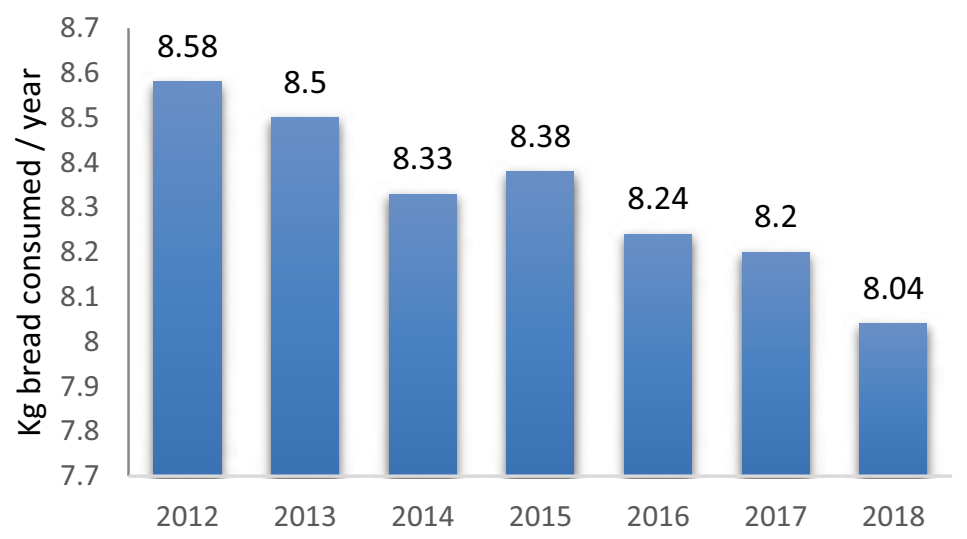

Fig. 1. Average bread consumption in Romania for the period 2012-2018.

On the other hand, consumer acceptability is a sine-qua-non condition for launching such new products. In what follows are presented the research method and the results obtained following a test performed in March 2019 at the Transylvania University of Brasov.

\section{Materials and methods}

\subsection{Materials}

The bread samples were made using the following raw materials:

- $\quad$ white wheat flour, type 480, supplier M.P. Băneasa - Moară S.A., Ilfov, Romania;

- flour - powder from mechanically degreased grape seeds, from Romanian fruits, supplier SC 2Eprod SRL, Teleorman, Romania;

- $\quad$ bakery yeast, (Saccharomyces cerevisiae), supplier Rompak SRL, Pașcani, Romania;

- $\quad$ iodized salt for the food industry - Sodium chloride $(\mathrm{NaCl})$ - minimum 97,50\% , substances insoluble in water - maximum $1,20 \%$, humidity - maximum $0,15 \%$, potassium iodate (KIO3) - min. $42 \mathrm{mg} / \mathrm{kg}$ - max. 67,20 mg/kg (according to HG 568/2002 republished) It is treated with anti-caking agent - potassium ferrocyanide (E 536), maximum $10 \mathrm{mg} / \mathrm{kg}$; Granulation: $0-2 \mathrm{~mm}$ (rest on the sieve of $2 \mathrm{~mm}$, max. $15 \%$ ). The product meets all the quality conditions provided in SR 13360/1996, STAS 2906, HG 568/2002 - republished;

- drinking water, temperature $22-25^{\circ} \mathrm{C}$.

Main recipe reported to $1 \mathrm{~kg}$ flour contains $700 \mathrm{ml}$ water, $20 \mathrm{~g}$ yeast, $20 \mathrm{~g}$ salt and $60 \mathrm{~g}$ sugar.

11 samples of bread, weighting $600 \mathrm{~g}$ each were made using direct and indirect method, by adding different quantities of grape seed flour (GSF), as following:

- P0d: $0 \%$ - represents the control bread sample with direct method;

- P1d: 3\% -represents the bread sample with direct method with an addition of 3\% GSF;

- P2d: 5\% -represents the bread sample with direct method with an addition of 5\% GSF;

- P3d: 7\% -represents the bread sample with direct method with an addition of 7\% GSF; 
- P4d: 9\% -represents the bread sample with direct method with an addition of 9\% GSF;

- P0i: $0 \%$ - represents the control bread sample with indirect method;

- P1i:3\%-represents the bread sample with indirect method with an addition of 3\% GSF;

- P2i:5\%-represents the bread sample with indirect method with an addition of 5\% GSF;

- P3i:7\%-represents the bread sample with indirect method with an addition of 7\% GSF;

- P4i:9\%-represents the bread sample with indirect method with an addition of 9\% GSF;

- PN - represents the control black bread sample for comparison.

Technological process by direct method followed next phases:

$\checkmark$ raw material conditioning (heating at $20^{\circ} \mathrm{C}$, dosing, yeast activation);

$\checkmark$ mixing (mixer Silver 50 NOVAPAN company, vat capacity: 551, mixing arm speed: $80 \mathrm{rot} / \mathrm{min}$, mixer vat speed: $25 \mathrm{rot} / \mathrm{min}$, mixing time: $25 \mathrm{~min}$ );

$\checkmark$ fermentation I in mixer ( $35 \mathrm{~min}$, at $20^{\circ} \mathrm{C}$ temperature);

$\checkmark$ division with divider SQSA/Vitella, in 10 equal pieces of $500 \mathrm{~g}$ dough;

$\checkmark$ fermentation II for $35 \mathrm{~min}$ at $33^{\circ} \mathrm{C}$ and $80 \%$ humidity;

$\checkmark$ baking in the oven (AST/ Tagliavini - Italia) for $45 \mathrm{~min}$ at $220^{\circ} \mathrm{C}$;

$\checkmark$ Technological process by indirect method followed next phases:

$\checkmark$ raw material conditioning (heating at $20^{\circ} \mathrm{C}$, dosing);

$\checkmark$ leaven preparation: $40 \%$ flour, $82 \%$ water, mixing time: $10 \mathrm{~min}$, fermentation time: $4 \mathrm{~h} ;$

$\checkmark$ mixing (60\% flour, 18\% water) (mixer Silver 50 NOVAPAN company, vat capacity: 551, mixing arm speed: $80 \mathrm{rot} / \mathrm{min}$, mixer vat speed: $25 \mathrm{rot} / \mathrm{min}$, mixing time: $25 \mathrm{~min}$ );

$\checkmark$ fermentation I in mixer (35 $\mathrm{min}$, at $20^{\circ} \mathrm{C}$ temperature);

$\checkmark$ division with divider SQSA/Vitella, in 10 equal pieces of $500 \mathrm{~g}$ dough;

$\checkmark$ fermentation II for $35 \mathrm{~min}$ at $33^{\circ} \mathrm{C}$ and $80 \%$ humidity;

$\checkmark$ baking in the oven (AST/ Tagliavini - Italia) for $45 \mathrm{~min}$ at $220^{\circ} \mathrm{C}$.

\subsection{Research method for sensorial analysis of bread samples}

The scoring method is the use of requirements to assess the intensity of a sensory property or characteristic (sensory attribute). This method is widely applied and is used for the quantitative evaluation of a set of sensorial properties (appearance, smell, taste, color, etc.) of food $[11,12]$.

The first stage of the sensory method is to establish the team of evaluators (panel), by selection based on the questionnaire, followed by the training of the panel for the sensory evaluation of the products to be tested.

The second stage consists in the elaboration of the sensory analysis sheet. After the individual evaluation, the sensory analysis sheets are centralized and a calculation method is applied to evaluate the results. If the evaluation panel consists of $\mathrm{N}$ evaluators and $\mathrm{n}$ is the number of sensory attributes established for evaluation, it results that each product sample will receive a total of ( $\mathrm{N} \mathrm{x} \mathrm{n)} \mathrm{scores} \mathrm{(appreciations),} \mathrm{meaning} \mathrm{each} \mathrm{evaluator} \mathrm{gives} \mathrm{a}$ score to each evaluation criterion (attribute) for each of the samples analyzed and tasted.

The total score (Ptot) that a sensory characteristic " $\mathrm{i}$ " receives from all " $\mathrm{N}$ " evaluators is given by formula 1 .

$$
(\text { Ptot }) i=\sum N j=1(\text { Pind } i) j=\text { Pind } 1+\text { Pind } 2+\cdots \text { Pind } N
$$

Where (Pind $\mathrm{i}) \mathrm{j}$ is the individual score given by the evaluator " $\mathrm{j}$ " for the characteristic "i";

$\mathrm{N}$ - the total number of evaluators in the panel.

The average score given to characteristic ' $i$ ' is given by formula 2 . 


$$
(P \text { med }) i=\frac{\sum N j(\text { Pind } i) j}{N}=\frac{(\text { Pind } 1+\text { Pind } 2+\ldots \text { Pind } N)}{N}
$$

For the analysis of the sensory characteristics from the evaluation sheet, several scoring systems are used, of which we used the 5-point scoring system.

Bread samples obtained from flour mixtures with the addition of partially defatted grape seed flour (GSF) were subjected to sensory analysis using the method of assessing sensory quality by scoring.

The panel evaluations of the sensory properties of the bread samples were performed at the Transilvania University of Brasov, at the student canteen of the university. Bread samples were subjected to sensory analysis after processing, cooling and storage, so that they are in similar conditions of consumption as the usual bread assortments in the bakery sales network. Bread samples were evaluated one day after baking, after cooling and storage at ambient temperature. The selection, preparation and monitoring of the persons who participated in the sensory evaluation of the bread samples were made in compliance with the provisions of the standards. ISO 8686-1 and ISO 8586-2 (Sensory analysis General guidance for the selection, training and monitoring of assessors, Part 1: Selected assessors and Part 2: Experts).

\begin{tabular}{|l|l|}
\hline \multicolumn{1}{|c|}{ Pre-selection questionnaire } & \multicolumn{2}{|l|}{ Answers } \\
\hline GENERAL INFORMATION'S & \\
\hline Name & \\
\hline Surname & \\
\hline Age & \\
\hline Studies & \\
\hline TIME/Motivation & Yes or No \\
\hline Are you interested in food tasting? & \\
\hline $\begin{array}{l}\text { Are you particularly interested in a certain category of food } \\
\text { products? }\end{array}$ & \\
\hline SKILLS & Yes or No \\
\hline Have you ever participated to a sensory analysis? & \\
\hline $\begin{array}{l}\text { HEALTH } \text { - Do you fall into one or more of the following } \\
\text { situations? }\end{array}$ & \\
\hline Diabetes & \\
\hline Hypoglycemia & \\
\hline Oral or gum problems & \\
\hline Hypertension & \\
\hline Food allergies & \\
\hline Smoker & \\
\hline EATING HABITS & \\
\hline How often in a month you eat in the city? & \\
\hline How often in a month you eat frozen food? & \\
\hline What is (are) your favorite food (s)? & \\
\hline What is (are) the food (s) you appreciate the least? & \\
\hline What food products you can not eat? & \\
\hline What kind of food products you do not like to eat? & \\
\hline
\end{tabular}

Fig. 2. Pre-selection questionnaire.

The main criteria underlying the selection process of each evaluator in the panel were the following: scientific interest and motivation, sincerity in reporting sensations, the ability to differentiate the specific characteristics of the evaluated product (bread), health, ability to memorize and to communicate sensory impressions.

Taking into account these criteria, the pre-selection questionnaire of the evaluators from the panel was elaborated (Fig. 2.). 
Each evaluator completed the individual sensory analysis sheets, with slices of bread from each bread sample analyzed, for comparative tasting and bread sections for comparative analysis of the appearance and texture of the samples. Experimental samples of bread with the addition of partially skimmed grape seed flour were analyzed sensorial, comparatively, both to white bread and to black bread, and between them, to determine the optimal percentage of acceptable ingredients in terms of sensory view to be added to white bread in order to achieve a product with functional potential.

Table 1. Defining sensory attributes on 5-point scale.

\begin{tabular}{|c|c|c|}
\hline $\begin{array}{l}\text { Sensory } \\
\text { attribute }\end{array}$ & \multicolumn{2}{|r|}{ Attribute definition } \\
\hline \multirow{5}{*}{$\begin{array}{l}\text { Exterior and } \\
\text { interior } \\
\text { appearance } \\
\text { (without } \\
\text { tasting) }\end{array}$} & Crust color & 1 - pale, light color ...5 - very intense color \\
\hline & Crumb color & 1 - pale, light color .. 5 - very intense color \\
\hline & $\begin{array}{l}\text { Uniformity of crumb } \\
\text { pores }\end{array}$ & $1-$ uneven pores...5 - even pores \\
\hline & Crumb softness & 1- hard core...5 - very soft core \\
\hline & Crumb friability & 1- very brittle... 5 - not brittle at all \\
\hline \multirow{5}{*}{ Flavor } & \multicolumn{2}{|r|}{ Basic tastes } \\
\hline & Bitter & $\begin{array}{l}\text { 1- weak, imperceptible aroma...5- } \\
\text { pronounced flavor }\end{array}$ \\
\hline & Salty & $\begin{array}{l}\text { 1- weak, imperceptible aroma...5 - } \\
\text { pronounced flavor }\end{array}$ \\
\hline & Sour & $\begin{array}{l}\text { 1- weak, imperceptible aroma ...5- } \\
\text { pronounced flavor }\end{array}$ \\
\hline & $\begin{array}{l}\text { Specific flavor - Note } \\
\text { the intensity of the } \\
\text { flavor: }\end{array}$ & $\begin{array}{l}\text { 1- weak, imperceptible aroma ...5 - } \\
\text { pronounced flavor }\end{array}$ \\
\hline After-taste & $\begin{array}{l}\text { Persistence of aroma } \\
\text { after chewing and } \\
\text { swallowing }\end{array}$ & $\begin{array}{l}1 \text { - imperceptible after taste } \ldots .5 \text { - very } \\
\text { pronounced after-taste }\end{array}$ \\
\hline
\end{tabular}

For the 10 characteristics established in the sensory evaluation of the bread samples, equal importance factors were established, thus interpreting the results using the arithmetic mean of the scores received by each sample. This simplified calculation method was chosen as it is a comparative analysis in the development process of a new bakery product.

Table 1. describes the sensory attributes and the score for each attribute used in the sensory assessment sheet.

\section{Results}

Following the experiments performed on a group of 15 panelists, the values of the average scores obtained at the sensory evaluation that were obtained are shown in table 2 .

In figure 3 are represented graphically comparatively the results regarding the characteristics: crumb color, uniformity of crumb pores, crumb softness and crumb friability.

In figure 4 are represented graphically comparatively the following characteristics: the bitter, salty and sour flavors, the intensity of the specific flavor and the persistence of the aroma after chewing and swallowing. The analysis of the table shows the change in shell color, core color, core pore uniformity, core flexibility, core friability, bitter taste, salty taste, sour taste, specific aroma, aroma persistence after chewing and swallowing with the change in the amount of seed flour in the recipe. 
Table 2. Summary of the scores obtained from the experimental bread samples with the addition of partially defatted grape seed flour (GSF).

\begin{tabular}{|c|c|c|c|c|c|c|c|c|c|c|}
\hline 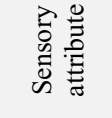 & \multirow{2}{*}{ 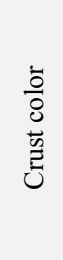 } & \multirow{2}{*}{ 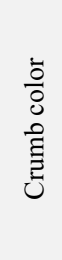 } & \multirow{2}{*}{ 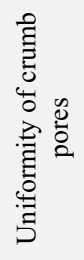 } & \multirow{2}{*}{ 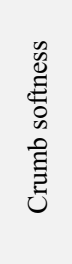 } & \multirow{2}{*}{ 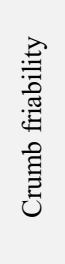 } & \multirow{2}{*}{ 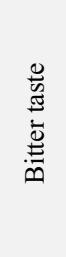 } & \multirow{2}{*}{ 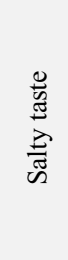 } & \multirow{2}{*}{ 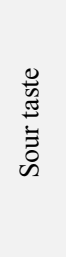 } & \multirow{2}{*}{ 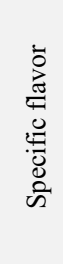 } & \multirow{2}{*}{ 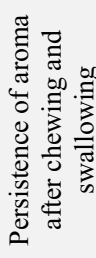 } \\
\hline 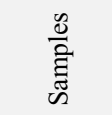 & & & & & & & & & & \\
\hline P0d:0\% & 1,51 & 1,17 & 3,51 & 4,32 & 2,16 & 1,17 & 1,42 & 1,42 & 2,66 & 1,66 \\
\hline P0i: $0 \%$ & 1,37 & 1,05 & 3,88 & 4,71 & 2,25 & 1,15 & 1,44 & 1,51 & 2,97 & 1,77 \\
\hline P1d: $3 \%$ & 2,05 & 3,67 & 3,62 & 4,12 & 2,99 & 1,21 & 1,46 & 2,12 & 2,73 & 2,02 \\
\hline P1i: $3 \%$ & 1,84 & 3,21 & 4,01 & 4,47 & 3,11 & 1,18 & 1,45 & 2,27 & 3,04 & 2,15 \\
\hline P2d: $5 \%$ & 2,57 & 4,06 & 3,87 & 3,88 & 3,84 & 1,87 & 1,49 & 2,46 & 2,81 & 2,78 \\
\hline P2i: $5 \%$ & 2,29 & 3,55 & 4,29 & 4,19 & 4,01 & 1,88 & 1,47 & 2,63 & 3,16 & 2,96 \\
\hline P3d: $7 \%$ & 3,04 & 4,42 & 4,02 & 3,67 & 4,32 & 2,54 & 1,50 & 2,79 & 2,9 & 3,53 \\
\hline P3i: 7\% & 2,73 & 3,87 & 4,45 & 3,98 & 4,52 & 2,51 & 1,51 & 2,96 & 3,23 & 3,76 \\
\hline P4d: $9 \%$ & 3,48 & 4,81 & 4,21 & 3,47 & 4,63 & 3,01 & 1,52 & 3,14 & 3,03 & 4,37 \\
\hline P4i: 9\% & 3,12 & 4,24 & 4,68 & 3,76 & 4,87 & 3,02 & 1,55 & 3,34 & 3,39 & 4,66 \\
\hline PN & 1,51 & 1,17 & 3,51 & 4,32 & 2,16 & 1,17 & 1,42 & 1,42 & 2,66 & 1,66 \\
\hline
\end{tabular}

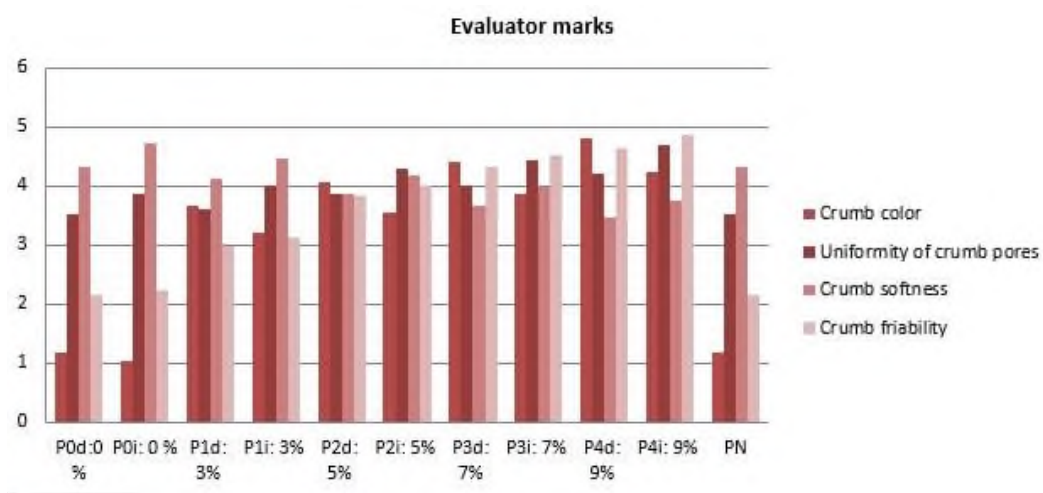

Fig. 3. Research results on consumer acceptability for the characteristics: Crumb color, Uniformity of crumb pores, Crumb softness and Crumb friability.

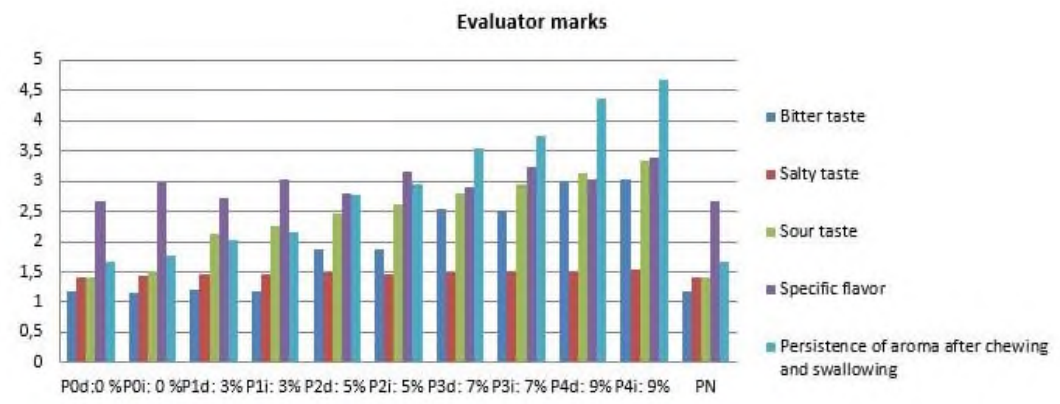

Fig. 4. Research results on consumer acceptability for the characteristics: Bitter taste, Salty tast, Sour taste, Specific flavor and Persistence of aroma after chewing and swallowing. 


\section{Discussions}

Figure 3 shows the increase of the values corresponding to the color of the core directly proportional to the GSF content variant $5 \%$ the indirect method, being similar to that of black bread. The uniformity of the pores increases with the increase of the addition of GSF variant $5 \%$ indirect method, being similar to that of black bread.

The friability of the core increases with the increase of the addition of GSF, the $5 \%$ indirect method, being similar to that of black bread.

The results shown in figure 4 also indicate that the taste indicators are close to those of black bread with GSF additions around 5\% value.

Future research will be conducted on the use of grape epicarp as an addition to bread making recipes. Theoretical and experimental analyzes will be performed regarding the chemical composition, the nutritional profile, the rheological behavior of the dough and the sensory analysis $[13,14,15]$. Different degrees of replacement of wheat flour with grape epicarp flour are considered, such as: $5 \%, 7.5 \%, 10 \%, 12.5 \%$.

\section{Conclusions}

Improving bakery products with the addition of GSF is a fast and efficient method of increasing the content of minerals and fibers. The paper studied the level of consumer acceptability for different degrees of replacement of GSF for the 2 technologies, direct and indirect method.

The results of the experimental research show that a degree of replacement of $5 \%$ with GSF allows obtaining sensory characteristics close to black bread, made according to the standard SR 878/1996.

\section{References}

1. L. Apostol, N. Belc, L. Gaceu, V. Vladut, O.B. Oprea, Chemical composition and rheological parameters of helianthus tuberosus flour used as a source of bioactive compounds in bakery, Rev. Chim. 70, 6, 2048 - 2053, ISSN 0034-7752 (2019)

2. G. Gadei, L. Gaceu, R. Gruia, Preliminary research regarding the impact of mustard flour addition in bread, JEAT 135-139 (2012)

3. L. Gaceu, R. Gruia, W. Thierheimer, Applications of a model simulation referring to the energetic flow transformities in agroecosystems, Proceedings of the 8th WSEAS International Conference on System Science and Simulation in Engineering (ICOSSSE '09), 41-46 (2009)

4. C.P.F. Marinangelia, P.J.H. Jones, Gazing into the crystal ball: future considerations for ensuring sustained growth of the functional food and nutraceutical marketplace, Br. J. Nutr. 26, 12-21 (2013)

5. O.B. Oprea, L. Gaceu, Application of Multiple Criteria Decision Making (MCDM) in bakery industry. Study Case: Wastes and By-Products, BUT, Series II: Forestry, Wood Industry, Agricultural Food Engineering 9 (58), 1 (2016)

6. O.B. Oprea, L. Gaceu, Preliminary researches on using spices in Traditional bakery product recipes, JEAT 7, 2, 15-18, ISSN: 1844-8577 (2011)

7. M. Niva, Consumers and the conceptual and practical appropriation of functional foods, Tampereen yliopistopaino, ISBN 978-951+698-174-4 (2008) 
8. O.B. Oprea, R. Gruia, Study on the level of grape seed flour (\%) addition in wheat flour upon the characteristics of bread dough, JEAT 13, 2, 175-179, ISBN: 1844-8577 (2016)

9. O.B. Oprea, Comparative studies regarding the use of grape seed powder (GSP) in bakery products, JEAT 13, 1, 34-41, ISBN: 1844-8577 (2017)

10. O.B. Oprea, L. Apostol, S. Bungau, G. Cioca, A.D. Samuel, M. Badea, L. Gaceu, Researches on the Chemical Composition and the Rheological Properties of Wheat and Grape Epicarp Flour Mixes, Rev.Chim. 69, 1, 70-75, ISSN 2537-5733 (2018)

11. L. Apostol, L. Berca, C. Mosoiu, M. Badea, S. Bungau, O.B. Oprea, G. Cioca, Partially Defatted Pumpkin (Cucurbita maxima) Seeds-a Rich Source of Nutrients for Use in Food Products, Rev.Chim. 69, 6, 70-75, ISSN 1398-1402 (2018)

12. O.B. Oprea, L. Gaceu, Optimization of Image Analysis Techniques for Quality Assessment of Wheat Bread with Grape Seed Flour Substitution, JEAT 15, .2(39), 8996, ISSN: 1844-8577 (2019)

13. O.B. Oprea, L. Gaceu, D. Tucu, Valorisation of winery waste by using GSP (grape seed powder) as flour substitution in bakery industry, Proceedings of the 45th International Symposium on Agricultural Engineering „Actual Tasks on Agricultural Engineering" 371 - 376, Opatija, ISSN 1848-4425 (2017)

14. M. Frioui, L. Gaceu, O.B. Oprea, M. Shamtsyan, The influence of fungal extract containing beta beta-glucans on the rheological characteristics of dough, Bulletin of the International Academy of Refrigeration 3, 53-61 (2018)

15. M. Frioui, M. Shamtsyan, L. Gaceu, O.B. Oprea, D. Mnerie, Rheological influence of (1-3)(1-6) mushrooms $\beta$-Glucan, used as flour substitution in bakery industry, Proceedings of the 45th International Symposium on Agricultural Engineering „Actual Tasks on Agricultural Engineering" 377 - 384, Opatija, ISSN 1848-4425 (2017) 